\title{
Q-Learning Induced Artificial Bee Colony for Noisy Optimization
}

\author{
Pratyusha Rakshit ${ }^{1}$, Amit Konar ${ }^{2}$ \\ ${ }^{1}$ Basque Center for Applied Mathematics, Bilbao, Spain \\ ${ }^{1,2}$ Department of Electronics and Telecommunication Engineering \\ Jadavpur University, Kolkata, India \\ 1'pratyushar1@gmail.com, ${ }^{2}$ konaramit@yahoo.co.in
}

Abstract - The paper proposes a novel approach to adaptive selection of sample size for a trial solution of an evolutionary algorithm when noise of unknown distribution contaminates the objective surface. The sample size of a solution here is adapted based on the noisy fitness profile in the local surrounding of the given solution. The fitness estimate and the fitness variance of a sub-population surrounding the given solution are jointly used to signify the degree of noise contamination in its local neighborhood (LN). The adaptation of sample size based on the characteristics of the fitness landscape in the LN of a solution is realized here with the temporal difference Q-learning (TDQL). The merit of the present work lies in utilizing the reward-penalty based reinforcement learning mechanism of TDQL for sample size adaptation. This sidesteps the prerequisite setting of any specific functional form of relationship between the sample size requirement of a solution and the noisy fitness profile in its $L N$. Experiments undertaken reveal that the proposed algorithms, realized with artificial bee colony, significantly outperform the existing counterparts and the state-of-the-art algorithms.

Keywords - artificial bee colony; noise-handling; temporal difference Q-learning; reinforcement learning; sampling.

\section{INTRODUCTION}

The reliance of real world optimization problems on evolutionary algorithms (EAs) has been widely observed over the past decades. The real world system characteristic is captured by the objective function of an EA, which is optimized for ensuring optimal utilization of system resources. However, the efficacy of the traditional EAs degrades with creeping of noise in the measurement of input data of the real world systems, primarily due to degraded sensor characteristics and/or noisy ambience. Edging of noise in the input measurement also induces inaccuracy in the assessment of objective function value (often called fitness) of a population member of an EA. Noisy fitness measurements of quality (and poor) solutions deceive the evolutionary selection operator by rejecting (and accepting) them over the generations. Consequently, the traditional EA fails to track the true global optimum in the presence of noise in the fitness landscape. The intricacy of the problem increases with noise of unknown stochastic distribution contaminating multimodal fitness landscape. It has thus called the amendment of the traditional EAs to overcome the illusive effect of noise. This class of optimization algorithm devised to alleviate the problem is referred to as noisy optimization [1], [2].

\author{
Atulya K. Nagar \\ Department of Mathematics and Computer Science, Liverpool Hope \\ University, United Kingdom \\ nagara@hope.ac.uk \\ nagara@iope.ac.uk
}

The well-known strategies used in noisy optimization algorithms include sampling [3-9], effective estimation of fitness [10], [11], dynamic population sizing [12], [13], improved search dynamics [14], [15] and robust selection operator [16], [17]. Among these, the most significant stratagem is sampling, where the fitness of a solution is periodically evaluated for a number of times, called sample size. An aggregate measure of these fitness samples thus obtained is used as the fitness estimate of the given solution. The multiple fitness evaluation of a solution increases the accuracy in its fitness assessment in the presence of noise of unknown distribution.

Evidently, a large sample size ensures fitness accuracy but at the cost of computational overhead. To overcome this impasse, dynamic sampling policies are developed in the recent past [3-9]. Among the existing strategies, sequential sampling [3], progress based dynamic sampling strategy [4], noise analysis selection [5], and optimal computing budget allocation [6] need special mentioning. The major constraint of the existing strategies is to overlook the level of contamination of noise in the local neighbourhood of a solution to determine its sampling requirement.

This issue has been addressed by the authors' previous works [7-9]. The variance of fitness estimates of a subpopulation surrounding the given solution is used to capture the degree of creeping of noise in its local neighbourhood. It is referred to as local neighbourhood fitness variance (LNFV). Different monotonically increasing functional forms have been used to model the relationship between LNFE and the sample size required for a solution [7-9]. Experiments undertaken reveal that a specific functional form cannot guarantee optimal assignment of sample size to a solution for all possible distribution of noise in the fitness landscape.

The paper proposes an alternative approach to bypass the need of a particular functional form to determine the sample size of a solution based on its LNFV. In addition to the LNFV, the policy also adapts sample size based on the local neighborhood fitness estimate (LNFE). The LNFV and LNFE are jointly used to capture the noise-contaminated fitness profile in the local vicinity of a solution. The reward and penalty based reinforcement learning mechanism of temporal difference Q-learning (TDQL) [18], [19] is used to prudently assign sample size (similar to action of TDQL) to a solution based on its local fitness profile, jointly captured by its 
respective LNFV and LNFE (similar to states of TDQL). If the assignment of a sample size $n$ to a solution by the TDQL increases LNFE (for maximization problem) and simultaneously reduces the respective LNFV, the selection is rewarded. Otherwise, the selection is penalized. These reward and penalties are encoded in the Q-values which in turn guide population of next generations to judiciously select their sample sizes.

In the present work, the artificial bee colony [20] is selected as the EA. The performance of the proposed noisy single objective optimization algorithm, referred to as $Q$ learning induced noisy bee colony (QLNBC), is compared with four state-of-the-art techniques [21-24]. The proposed adaptive sampling strategy is also used to replace the sampling policy recommended in [25] and results in a new competitor in the comparative framework, called extended QLNBC. The comparative performance is analyzed with respect to function error value metric while optimizing noisy versions of 28 CEC'2013 benchmark functions [26]. The benchmark functions are contaminated with additive noise samples taken from Gaussian [27], Poisson [28], Rayleigh [29], exponential [30], and random distribution [31]. Experiments undertaken reveal that the proposed realizations outperform other algorithms in a statistically significant manner. The Wilcoxon test, the Friedman and Iman-Davenport non-parametric tests and the Bonferroni-Dunn post-hoc analysis [32] are undertaken to arrive at the conclusion.

The paper is divided into six sections. Section II overviews the traditional ABC and the TDQL algorithms. A brief outline of the existing sample size adaptation policies is given in section III. Section IV provides the noise handling mechanism used to extend the ABC. Simulation results are reported in section V. Section VI concludes the paper.

\section{PRELIMINARIES}

\section{A. Artificial Bee Colony Algorithm}

Artificial bee colony (ABC) [20] is a population-based meta-heuristic algorithm. An overview of the main steps of the $\mathrm{ABC}$ algorithm is presented next for maximization problem.

1. Initialization: $\mathrm{ABC}$ begins with a population $\mathbf{P}(t)$ of $S, D$ dimensional real-valued solutions $\left\{\vec{Z}_{1}(t), \vec{Z}_{2}(t), \ldots, \vec{Z}_{S}(t)\right\}$, randomly initialized within the search bound of the given optimization problem at generation $t=0$. The fitness value $\operatorname{fit}\left(\vec{Z}_{i}(0)\right)$ of $\vec{Z}_{i}(0)$ is evaluated for $i=1,2, \ldots, S$.

2. Employed Bee Phase: In this phase, a randomly chosen parameter $\left(j \in\{1,2, \ldots, D\}\right.$ of a solution $\vec{Z}_{i}(t)$ is modified to generate an offspring solution $\vec{Z}_{i}^{\prime}(t)$ following (1) for $i=1,2$, $\ldots, S$. The remaining $D-1$ components of $\vec{Z}_{i}^{\prime}(t)$ are identical to that of $\vec{Z}_{i}(t)$.

$$
z_{i, j}^{\prime}(t)=z_{i, j}(t)+F \times\left(z_{i, j}(t)-z_{k, j}(t)\right)
$$

Here $\vec{Z}_{k}(t)$ is a solution selected randomly from $\mathbf{P}(t) \backslash \vec{Z}_{i}(t)$ and $F$ represents the scale factor in $(-1,1) . \vec{Z}_{i}(t)$ is replaced by $\vec{Z}_{i}^{\prime}(t)$, if $\operatorname{fit}\left(\vec{Z}_{i}^{\prime}(t)\right) \geq \operatorname{fit}\left(\vec{Z}_{i}(t)\right)$.
3. Probability of Selection by Onlookers: This step is concerned with assigning a high probability of selection to a solution with better fitness for the subsequent step. In other words, the selection probability of $\vec{Z}_{i}(t)$ with fitness $\operatorname{fit}\left(\vec{Z}_{i}(t)\right)$ is calculated using (2) for $i=1,2, \ldots, S$.

$$
p s_{i}=f i t\left(\vec{Z}_{i}(t)\right) / \sum_{j=1}^{S} f i t\left(\vec{Z}_{j}(t)\right)
$$

4. Onlooker Bee Phase: The $q$-th onlooker probabilistically selects a solution $\vec{Z}_{i}(t) \in \mathbf{P}(t)$ based on $p s_{i}$ and employs (1) to generate a new solution $\vec{Z}_{i}^{\prime}(t) . \vec{Z}_{i}^{\prime}(t)$ replaces $\vec{Z}_{i}(t)$ in the next generation $t+1$ provided $\operatorname{fit}\left(\vec{Z}_{i}^{\prime}(t)\right) \geq \operatorname{fit}\left(\vec{Z}_{i}(t)\right)$. This step is repeated for all onlooker bees with $q=1,2, \ldots, S$.

5. Scout Bee Phase: This step deals with random reinitialization of a population member (within predefined search boundary) remaining unchanged for a predefined number of generations, called 'limit'.

6. Convergence: After each evolution cycle, steps 2 to 5 are repeated until terminating criterion is satisfied.

\section{B. Temporal Difference Q-Learning}

Q-learning is a well-known member of the class of reinforcement learning [18], [19]. In Q-learning, an agent at a given state $\tau_{i} \in\left\{\tau_{1}, \tau_{2}, \ldots, \tau_{M}\right\}$ selects and executes an action $\alpha_{j}$ from a set of possible $N$ actions $\left\{\alpha_{1}, \alpha_{2}, \ldots, \alpha_{N}\right\}$ and eventually receives an immediate reward/penalty $r\left(\tau_{i}, \alpha_{j}\right)$ from its environment. It helps the agent to learn a control policy to reach a definite goal by increasing the possibility of its correct response.

Let,

$Q\left(\tau_{i}, \alpha_{j}\right)$ be the quality factor of the state-action pair $<\tau_{i}$, $\alpha_{j}>$ encoding the total reward that the agent acquires by execution of an action $\alpha_{j}$ at state $\tau_{i}$.

$\delta\left(\tau_{i}, \alpha_{j}\right)$ be the transition function that returns the next state $\tau_{k} \in\left\{\tau_{1}, \tau_{2}, \ldots, \tau_{M}\right\}$ of the agent due to execution of action $\alpha_{j}$ at state $\tau_{i}$.

To ensure unbiased selection of actions in the initial phase, equal Q-value is assigned to each state-action pair. At a particular instant of Q-learning, the agent occupies a state $\tau_{i} \in\left\{\tau_{1}, \tau_{2}, \ldots, \tau_{M}\right\}$, consults the Q-values $Q\left(\tau_{i}, \alpha_{l}\right)$, for $l=1,2$, $\ldots, N$ to select and execute an action $\alpha_{j} \in\left\{\alpha_{1}, \alpha_{2}, \ldots, \alpha_{N}\right\}$. The agent consequently receives an immediate reward $r\left(\tau_{i}, \alpha_{j}\right)$ and moves to the new state $\tau_{k}$ using $\delta$-transition rule. The Q-value $Q\left(\tau_{i}, \alpha_{j}\right)$ is then updated based on the immediate reward $r\left(\tau_{i}, \alpha_{j}\right)$ and the cumulative reward expected by the agent in subsequent state-transitions from its next state $\tau_{k}$. The currently updated Qvalue is used to guide the agent to judiciously select its actions at state $\tau(i)$ in subsequent instants. Now, the next state $\tau_{k}=\delta\left(\tau_{i}\right.$, $\alpha_{j}$ ) is considered as the initial state, and the steps of action selection, receiving immediate reward, state-transition and Qvalue update are repeated forever.

Evidently, the reinforcement learning policy used to update the Q-values plays the vital role to ensure the quality performance of Q-learning. According to the classical Qlearning, the updated $\mathrm{Q}$ value at state $\tau_{i}$ after execution of action $\alpha_{j}$ is given by (3). 


$$
\begin{aligned}
Q\left(\tau_{i}, \alpha_{j}\right) & =r\left(\tau_{i}, \alpha_{j}\right)+\gamma \max _{\alpha^{\prime}} Q\left(\delta\left(\tau_{i}, \alpha_{j}\right), \alpha^{\prime}\right) \\
& =r\left(\tau_{i}, \alpha_{j}\right)+\gamma \max _{\alpha^{\prime}} Q\left(\tau_{k}, \alpha^{\prime}\right)
\end{aligned}
$$

Here, $\gamma \in(0,1]$ denotes the discounting factor used to signify the importance of the cumulative future reward $\max _{\alpha^{\prime}} Q\left(\tau_{k}, \alpha^{\prime}\right)$. A factor of 0 implies an opportunist agent by considering only the immediate rewards, while $\gamma$ approaching 1 will make the agent strive for a long-term high reward.

The temporal difference Q-learning (TDQL) [18], [19] is a modified version of the classical Q-learning. In TDQL, the current Q-value at state-action pair $\left\langle\tau_{i}, \alpha_{j}\right\rangle$ is also used to update its value following (4).

$$
\begin{aligned}
Q\left(\tau_{i}, \alpha_{j}\right) \leftarrow(1-\beta) \times Q\left(\tau_{i}, \alpha_{j}\right)+ & \\
& \beta \times\left(r\left(\tau_{i}, \alpha_{j}\right)+\gamma \max _{\alpha^{\prime}} Q\left(\delta\left(\tau_{i}, \alpha_{j}\right), \alpha^{\prime}\right)\right.
\end{aligned}
$$

The learning rate $\beta \in(0,1)$ determines the degree of dominance of the newly acquired reward over the old information. Evidently, the agent stop learning with $\beta=0$, while $\beta=1$ allows the agent to consider the latest information only.

\section{OVERVIEW OF EXISTING SAMPLING POLICIES}

The primary objective of a noisy optimization problem is to estimate the true fitness of a candidate solution when the fitness landscape is contaminated with noise of unknown stochastic distribution. The infiltration of noise in the fitness measure of a quality solution may deprive it from promotion to the next generation population. On the contrary, a true inferior solution with deceptive noisy fitness value may occupy the next generation population.

To avoid this camouflaged presence of noise in the fitness measure of an offspring $\vec{Z}_{i}^{\prime}$ (generated from its parent $\vec{Z}_{i}$ through employed/onlooker bee phase), its fitness $\operatorname{fit}\left(\vec{Z}_{i}^{\prime}\right)$ is repeatedly evaluated for $n\left(\vec{Z}_{i}^{\prime}\right)$ times, called sample size. The strategy is referred to as sampling. An aggregate measure of the resulting $n\left(\vec{Z}_{i}^{\prime}\right)$ number of fitness samples of $f i t\left(\vec{Z}_{i}^{\prime}\right)$ is then used as the effective fitness estimate $\overline{\text { fit }}\left(\vec{Z}_{i}^{\prime}\right)$ [7-9]. The accuracy of the estimate $\overline{f i t}\left(\vec{Z}_{i}^{\prime}\right)$ is ascertained from the fitness variance $V\left(\vec{Z}_{i}^{\prime}\right)$ capturing the spread of $n\left(\vec{Z}_{i}^{\prime}\right)$ samples of $\operatorname{fit}\left(\vec{Z}_{i}^{\prime}\right)$ away from the fitness estimate $\overline{f i t}\left(\vec{Z}_{i}^{\prime}\right)$ [7-9]. The evaluations of effective fitness estimate $\overline{f i t}\left(\vec{Z}_{i}^{\prime}\right)$ and fitness variance $V\left(\vec{Z}_{i}^{\prime}\right)$ are omitted here due to space constraint. Interested readers may refer to [7-9] for the necessary background.

Evidently, proper selection of sample size is an essential step of noisy optimization problem to ensure accurate fitness measures of population members. Authors' previous works [7-9] are concerned with adaptive sampling strategy where each candidate solution $\vec{Z}_{i}^{\prime}$ is assigned with a sample size $n\left(\vec{Z}_{i}^{\prime}\right)$ based on noise-contamination level in its local neighborhood (LN). As the true distribution of noise in the fitness landscape is unknown, the fitness variance $\vartheta\left(\vec{Z}_{i}^{\prime}\right)$ of the solutions in the LN of $\vec{Z}_{i}^{\prime}$ is used to model the noisecontamination level in the respective LN. $\vartheta\left(\vec{Z}_{i}^{\prime}\right)$ is referred to as local neighbourhood fitness variance (LNFV) of $\vec{Z}_{i}^{\prime}$. Intuitively, a large (or a small) $\vartheta\left(\vec{Z}_{i}^{\prime}\right)$ indicates a large (or small) degree of intrusion of noise in the LN of $\vec{Z}_{i}^{\prime}$ demanding a large (or small) sample size $n\left(\vec{Z}_{i}^{\prime}\right)$. This in turn balances the trade-off between the degree of accuracy in the fitness estimate and the runtime.

The sample size $n\left(\vec{Z}_{i}^{\prime}\right)$ is modeled as a monotonically nondecreasing function of $\vartheta\left(\vec{Z}_{i}^{\prime}\right)$ in the existing works [7-9]. Symbolically,

$$
n\left(\vec{Z}_{i}^{\prime}\right)=g\left(\vartheta\left(\vec{Z}_{i}^{\prime}\right)\right)
$$

Here $g($.$) denotes the monotonically non-decreasing$ function used to predict sample size $n\left(\vec{Z}_{i}^{\prime}\right)$ based on LNFV $\vartheta\left(\vec{Z}_{i}^{\prime}\right)$. Different forms of $g($.$) have been adopted in [7-9].$

The existing approaches suffer from two limitations.

First, the methods predict sample size of an offspring $\vec{Z}_{i}^{\prime}$ based on its LNFV only, ignoring the varying convexity of the fitness landscape of its LN. Specifically, for a maximization problem, if $\vec{Z}_{i}^{\prime}$ falls in an LN with large fitness estimate, a large $n\left(\vec{Z}_{i}^{\prime}\right)$ is required to guarantee the true quality of $\vec{Z}_{i}^{\prime}$. Otherwise, a small value of $n\left(\vec{Z}_{i}^{\prime}\right)$ is used to reduce the runtime overhead. Hence, the first aim of the present work is to predict sample size $n\left(\vec{Z}_{i}^{\prime}\right)$ of $\vec{Z}_{i}^{\prime}$ jointly based on its LNFV $\vartheta\left(\vec{Z}_{i}^{\prime}\right)$ and local neighbourhood fitness estimate (LNFE) $\mu\left(\vec{Z}_{i}^{\prime}\right)$. $\vartheta\left(\vec{Z}_{i}^{\prime}\right)$ and $\mu\left(\vec{Z}_{i}^{\prime}\right)$ jointly capture the fitness profile of the LN of $\vec{Z}_{i}^{\prime}$. Mathematically,

$$
n\left(\vec{Z}_{i}^{\prime}\right)=g\left(\vartheta\left(\vec{Z}_{i}^{\prime}\right), \mu\left(\vec{Z}_{i}^{\prime}\right)\right) .
$$

Second, the judicious selection of the functional form $g($. greatly influences the efficacy of the sampling strategy. A specific functional form of $g($.$) being biased to the nature of$ stochastic distribution of noise in the fitness landscape, may not always predict the appropriate sample size required for all possible stochastic distribution of noise. This gridlock has been overcome here by employing TDQL-induced adaptive sampling policy which detours the need for a specific functional form of $g($.).

\section{PROPOSED METHOD}

This section elaborates the steps used to employ the TDQLinduced adaptive sampling policy.

\section{Local Neighborhood Formation}

The first step is concerned with dividing the search space into a number of local neighborhoods (LNs). First, for each candidate solution, we compute the following composite measure 


$$
\phi\left(\vec{Z}_{i}\right)=\left(1-\frac{\overrightarrow{f i t}\left(\vec{Z}_{i}\right)}{\sum_{j=1}^{S} \overline{f i t}\left(\vec{Z}_{j}\right)}\right) \times \frac{\vartheta\left(\vec{Z}_{i}\right)}{\sum_{j=1}^{S} \vartheta\left(\vec{Z}_{j}\right)}
$$

for $i=1,2, \ldots, S$. For a maximization problem, more the fitness measure $\overline{f i t}($.$) and small the fitness variance \vartheta($.$) , small$ is the composite measure $\varphi($.$) . The entire population is then$ sorted in ascending order of their respective composite measures. The candidate at the top most position of the sorted population $\mathbf{P}$ is selected as the first local guide $\vec{Z}^{1, l g}$ of the first $\operatorname{LN} \boldsymbol{\psi}_{1}$. The $\operatorname{LN} \boldsymbol{\psi}_{1}$ with local guide $\vec{Z}^{1, l g}$ is formed by the sub-population lying within the hyperspace bounded by $\left[\Delta \vec{Z}^{1, l}, \Delta \vec{Z}^{1, h}\right]$, where

$$
\begin{gathered}
\Delta \vec{Z}^{1, l}=\left\{z_{1}^{1, l g}-\Delta z_{1}, z_{2}^{1, l g}-\Delta z_{2}, \ldots, z_{D}^{1, l g}-\Delta z_{D}\right\} \\
\Delta \vec{Z}^{1, h}=\left\{z_{1}^{1, l g}+\Delta z_{1}, z_{2}^{1, l g}+\Delta z_{2}, \ldots, z_{D}^{1, l g}+\Delta z_{D}\right\}
\end{gathered}
$$

$$
\text { and } \quad \Delta z_{j}=\left(z_{j}^{h}-z_{j}^{l}\right) / S \quad \text { for } j=1,2, \ldots, D \text {. }
$$

Here, $z_{j}^{l}$ and $z_{j}^{h}$ respectively denote the minimum and maximum search boundary along the $j$-th dimension for $j$ $=1,2, \ldots, D$. To construct the second $\operatorname{LN} \psi_{2}$, the solution at the top most position of the sorted list $\left\{\mathbf{P}-\boldsymbol{\psi}_{1}\right\}$ is recorded as the second local guide $\vec{Z}^{2, l g}$. The subordinates of $\vec{Z}^{2, l g}$ lying within $\left[\Delta \vec{Z}^{2, l}, \Delta \vec{Z}^{2, h}\right]$ (following (8)) are included in the second LN $\boldsymbol{\psi}_{2}$.

This is repeated until each member of $\mathbf{P}$ is assigned to an LN and finally, the $D$-dimensional search space is segmented into a number of LNs. Let the number of LNs thus identified in the current generation be denoted by $C$.

\section{Fitness Estimate and Fitness Variance in Local Neighborhood}

The fitness profile of each LN (discovered in the last step) here is characterized by the effective fitness estimate and the fitness variance of their constituent population members, however, with different weights. Let $\vec{Z}_{l}^{j}$ be the $l$-th member of the $j$-th LN $\psi_{j}$ with its effective fitness estimate $\left.\overline{\operatorname{fit}}_{\left(Z_{l}^{j}\right.}^{j}\right)$ for $l$ $=1,2, \ldots,\left|\psi_{j}\right|$. Moreover, let $\xi_{l}^{j}$ be the average of effective fitness estimates of all population members of $\boldsymbol{\psi}_{j}$, however excluding $\left.\overline{\operatorname{fit}(} \vec{Z}_{l}^{j}\right)$. Mathematically,

$$
\xi_{l}^{j}=\frac{\sum_{k=1, k \neq l}^{\left|\Psi_{j}\right|} \overline{f i t}\left(\vec{Z}_{k}^{j}\right)}{\left|\boldsymbol{\Psi}_{j}\right|-1}
$$

for $l=1,2, \ldots,\left|\boldsymbol{\psi}_{j}\right|$. Next, we determine the weight of $\overline{\operatorname{fit}}\left(\vec{Z}_{l}^{j}\right)$, given by

$$
w_{l}=\exp \left(-\left|\overline{f i t}\left(\vec{Z}_{l}^{j}\right)-\xi_{l}^{j}\right|\right) .
$$

The design philosophy is based on the supposition that larger the value of $\left|\overrightarrow{f i t}\left(\vec{Z}_{l}^{j}\right)-\xi_{l}^{j}\right|$, greater is the degree of disagreement between effective fitness estimate of $\vec{Z}_{l}^{j}$ and other members of $\mathrm{LN} \boldsymbol{\psi}_{j}$, indicating possibility of $\overline{f i t}\left(\vec{Z}_{l}^{j}\right)$ to be noisy. Thus its significance towards calculation of LNFE of the entire $\mathrm{LN} \boldsymbol{\psi}_{j}$ must be reduced by assigning a small weight $w_{l}$. It is apparent from (10) that with an increase in $\left|\overrightarrow{f i t}\left(\vec{Z}_{l}^{j}\right)-\xi_{l}^{j}\right|, w_{l}$ tends to be reduced to zero. After evaluating the weights $0<w_{l}<1$ for all members of $\boldsymbol{\psi}_{j}$ for $l=$ $1,2, \ldots,\left|\psi_{j}\right|$, we obtain the local neighborhood fitness estimate (LNFE) of LN $\psi_{j}$, say $\mu_{j}$, as

$$
\mu_{j}=\sum_{l=1}^{\left|\Psi_{j}\right|}\left(w_{l} \times \overline{\operatorname{fit}}\left(\vec{Z}_{l}^{j}\right)\right) / \sum_{l=1}^{\psi_{j} \mid} w_{l} .
$$

Finally, the local neighborhood fitness variance (LNFV) of LN $\boldsymbol{\psi}_{j}$ is computed following (12).

$$
\vartheta_{j}=\left(\sum_{l=1}^{\left|\psi_{j}\right|} w_{l}\left(\overline{\operatorname{fit}}\left(\vec{Z}_{l}^{j}\right)-\mu_{j}\right)^{2}\right) /\left(\mid \sum_{l=1}^{\left|\psi_{j}\right|} w_{l}\right) .
$$

Once we obtain $\mu_{j}$ and $\vartheta_{j}$ for all neighborhoods $j=1,2, \ldots$, $C$ in a particular generation, the normalized LNFE $\mu_{j-\text { norm }} \in[0$, $1]$ and LNFV $\vartheta_{j \text {-norm }} \in[0,1]$ of $\psi_{j}$ are computed using (13) and (14) respectively for $j=1,2, \ldots, C$.

$$
\begin{gathered}
\mu_{j-\text { norm }}=\mu_{j} / \sum_{k=1}^{C} \mu_{k} \\
\vartheta_{j-\text { norm }}=\vartheta_{j} / \sum_{k=1}^{C} \vartheta_{k}
\end{gathered}
$$

\section{Design of $\mathbf{Q}$-Table}

The proposed adaptive sampling policy accesses a threedimensional Q-table to determine sample size of a solution from the pool $\{2,3, \ldots, N\}$ where $N$ denotes the maximum sample size. The solution is assigned to a state-pair in the Qtable based on its normalized LNFE and LNFV. The first dimension of the Q-table represents the possible set of $M$ states of population members based on their normalized LNFE $\mu_{\text {norm}}$, denoted by $\left\{\tau_{1}(1), \tau_{1}(2), \ldots, \tau_{1}(M)\right\}$. Similarly, the second dimension of the Q-table $\left\{\tau_{2}(1), \tau_{2}(2), \ldots, \tau_{2}(L)\right\}$ encodes $L$ possible states of the candidate solutions based on their normalized LNFV $\vartheta_{\text {norm }}$. The columns of the Q-table denote uniformly quantized values of the sample size $\{2,3$, $\ldots, N\}$, to be used for the periodic fitness evaluation of a solution.

The state $\tau_{1}(m) \in\left\{\tau_{1}(1), \tau_{1}(2), \ldots, \tau_{1}(M)\right\}$ represents normalized LNFEs in the range $[(m-1) / M, m / M)$ while the state $\tau_{2}(l) \in\left\{\tau_{2}(1), \tau_{2}(2), \ldots, \tau_{2}(L)\right\}$ symbolizes normalized LNFVs in the range $[(l-1) / L, l / L)$. In other words, a candidate solution $\vec{Z}$, belonging to the $\mathrm{LN} \psi_{j}$, is assigned to a state-pair 
$<\tau_{1}(m), \tau_{2}(l)>$ if the corresponding normalized LNFE $\mu_{j \text {-norm }} \in$ $[(m-1) / M, m / M)$ and the respective normalized LNFV $\vartheta_{j \text {-norm }}$ $\in[(l-1) / L, l / L)$ for $m \in\{1,2, \ldots, M\}$ and $l \in\{1,2, \ldots, L\}$. The component $Q\left(<\tau_{1}(m), \tau_{2}(l)>, \alpha\right)$ of the Q-table denotes the Q-value correponding to a sample size $\alpha \in\{2,3, \ldots, N\}$ at a specific state-pair $<\tau_{1}(m), \tau_{2}(l)>$ for $m \in\{1,2, \ldots, M\}$ and $l$ $\in\{1,2, \ldots, L\}$.

\section{Identification of Local Neihborhood of an Offspring}

Next, the employed/onlooker bee phase of $A B C$ is employed to generate an offspring $\vec{Z}_{i}^{\prime}$ from its respective parent $\vec{Z}_{i}$. To determine sample size for periodic fitness evaluation of $\vec{Z}_{i}^{\prime}$, its $\mathrm{LN} \psi_{j}$ is identified for $k \in\{1,2, \ldots, C\}$, by finding out the local guide $\vec{Z}^{k, l g}$ with the minimum distance from $\vec{Z}_{i}^{\prime}$ among all $C$ local guides.

\section{State-pair Assignment of a Trial Vector}

The normalized LNFE $\mu_{k \text {-norm }}$ and LNFV $\vartheta_{k \text {-norm }}$ are used to assign $\vec{Z}_{i}^{\prime}$ to a specific state-pair in the Q-table. If $\mu_{k \text {-norm }} \in[(m$ $-1) / M, m / M)$ and $\vartheta_{k-n o r m} \in[(l-1) / L, l / L), \vec{Z}_{i}^{\prime}$ is assigned to the state-pair $<\tau_{1}(m), \tau_{2}(l)>$ for $m \in\{1,2, \ldots, M\}$ and $l \in\{1,2, \ldots$, $L\}$.

\section{Adaptive Selection of Sample Size using Temporal} Difference Q-Learning

Once $\vec{Z}_{i}^{\prime}$ is assigned to a state-pair $\left\langle\tau_{1}(m), \tau_{2}(l)>\right.$, for $m \in\{1,2, \ldots, M\}$ and $l \in\{1,2, \ldots, L\}$, the TDQL is employed to select a sample size from $\{2,3, \ldots, N\}$ based on the Qvalues $Q\left(<\tau_{1}(m), \tau_{2}(l)>, \alpha\right)$ for $\alpha=2,3, \ldots, N$. The reward and penalty obtained during the selection of sample size $\alpha$ at statepair $<\tau_{1}(m), \tau_{2}(l)>$ in the previous generations are used to adapt the Q-values $Q\left(<\tau_{1}(m), \tau_{2}(l)>, \alpha\right)$ in the subsequent generations. If $Q\left(<\tau_{1}(m), \tau_{2}(l)>, \alpha\right) \geq Q\left(<\tau_{1}(m), \tau_{2}(l)>, \alpha^{\prime}\right)$ for $\alpha^{\prime}=2,3, \ldots, N$, it signifies that the selection of particular sample size $\alpha$ was rewarded many times before in the evolution process. The learning experience thus selects the sample size $n\left(\vec{Z}_{i}^{\prime}\right)=\alpha$ with the highest Q-value. The probability of selection of $n\left(\vec{Z}_{i}^{\prime}\right)=\alpha$ from the pool $\{2,3, \ldots$, $N\}$ at the state-pair $<\tau_{1}(m), \tau_{2}(l)>$ is given by

$$
p(m, l, \alpha)=\frac{Q\left(\left\langle\tau_{1}(m), \tau_{2}(l)\right\rangle, \alpha\right)}{\sum_{\alpha^{\prime}=2}^{N} Q\left(\left\langle\tau_{1}(m), \tau_{2}(l)\right\rangle, \alpha^{\prime}\right)}
$$

for $m=1,2, \ldots, M$ and $l=1,2, \ldots, L$. To maintain adaptation and learning in all Q's present in all possible state-pairs, the Roulette-choice strategy [19] is employed for selection of sample size. The strategy selects a sample size $\alpha$ from the pool $\{2,3, \ldots, N\}$ for an offspring $\vec{Z}_{i}^{\prime}$ at state-pair $\left\langle\tau_{1}(m), \tau_{2}(l)>\right.$ if the following condition holds where $\operatorname{rand}(0,1)$ denotes a random number uniformly distributed in $(0,1)$.

$$
\sum_{\alpha^{\prime}=1}^{\alpha-1} p\left(m, l, \alpha^{\prime}\right) \leq \operatorname{rand}(0,1) \leq \sum_{\alpha^{\prime}=1}^{\alpha} p\left(m, l, \alpha^{\prime}\right)
$$

\section{State-Transition}

The sample size $n\left(\vec{Z}_{i}^{\prime}\right)=\alpha$ selected for $\vec{Z}_{i}^{\prime}$ in the last step is used for its periodic fitness evaluation, effective fitness estimate $\overline{f i t}\left(\vec{Z}_{i}^{\prime}\right)$ and fitness variance $V\left(\vec{Z}_{i}^{\prime}\right)$, using the approaches proposed in [7-9]. The evaluated $\overline{f i t}\left(\vec{Z}_{i}^{\prime}\right)$ and $V\left(\vec{Z}_{i}^{\prime}\right)$ are now used to evaluate the new normalized LNFE and LNFV of $\psi_{k}$, the LN of $\vec{Z}_{i}^{\prime}$, using (11)(14). Let the currently obtained values of normalized LNFE and LNFV be denoted by $\mu_{k-\text { norm }}^{\text {cur }}$ and $\vartheta_{k-n o r m}^{\text {cur }}$. If $\mu_{k-\text { norm }}^{\text {cur }} \in[(x-1) / M, x / M)$ and $\vartheta_{k-\text { norm }}^{\text {cur }} \in[(y-1) / L, y / L)$, for $x \in\{1,2, \ldots, M\}$ and $y \in\{1,2, \ldots, L\}$, then $\vec{Z}_{i}^{\prime}$ is assigned to the new state-pair $\left\langle\tau_{1}(x), \tau_{2}(y)>\right.$ from its old state-pair $<\tau_{1}(m)$, $\tau_{2}(l)>$. Symbolically,

$$
\delta\left(\left\langle\tau_{1}(m), \tau_{2}(l)\right\rangle, \alpha\right)=\left\langle\tau_{1}(x), \tau_{2}(y)\right\rangle
$$

\section{Reward and Penalty based Update of Q-Table}

$$
\text { If } \mu_{k-\text { norm }}^{\text {cur }}>\mu_{k-\text { norm }} \text { (for maximization problem) or }
$$
$\vartheta_{k-\text { norm }}^{\text {cur }}<\vartheta_{k-\text { norm }}$, the selection of sample size $\alpha \in 2,3, \ldots$, $N$ at the state-pair $\left\langle\tau_{1}(m), \tau_{2}(l)\right\rangle$ is rewarded with the respective reward, given below.

$$
\begin{aligned}
\text { If } \mu_{k-\text { norm }}^{\text {cur }}> & \mu_{k-\text { norm }} \text { and } \vartheta_{k-\text { norm }}^{\text {cur }} \geq \vartheta_{k-\text { norm }} \\
& r\left(\left\langle\tau_{1}(m), \tau_{2}(l)\right\rangle, \alpha\right)=\mu_{k-\text { norm }}^{\text {cur }}-\mu_{k-\text { norm }} .
\end{aligned}
$$

If $\mu_{k-\text { norm }}^{\text {cur }} \leq \mu_{k-\text { norm }}$ and $\vartheta_{k-\text { norm }}^{\text {cur }}<\vartheta_{k-\text { norm }}$

$$
r\left(\left\langle\tau_{1}(m), \tau_{2}(l)\right\rangle, \alpha\right)=\vartheta_{k-\text { norm }}-\vartheta_{k-\text { norm }}^{\text {cur }} .
$$

If $\mu_{k-\text { norm }}^{\text {cur }}>\mu_{k-\text { norm }}$ and $\vartheta_{k-\text { norm }}^{\text {cur }}<\vartheta_{k-\text { norm }}$

$$
r\left(\left\langle\tau_{1}(m), \tau_{2}(l)\right\rangle, \alpha\right)=\left(\mu_{k-\text { norm }}^{\text {cur }}-\mu_{k-\text { norm }}\right)+\left(\vartheta_{k-\text { norm }}-\vartheta_{k-\text { norm }}^{\text {cur }}\right) .(18 . \mathrm{c})
$$

If $\mu_{k-\text { norm }}^{\text {cur }} \leq \mu_{k-\text { norm }}$ and $\vartheta_{k-\text { norm }}^{\text {cur }} \geq \vartheta_{k-\text { norm }}$, then the selection is penalized with

$$
r\left(\left\langle\tau_{1}(m), \tau_{2}(l)\right\rangle, \alpha\right)=-K
$$

with $K$ as a positive constant value, however, small.

The corresponding Q-value is then updated with

$$
\begin{aligned}
Q\left(\left\langle\tau_{1}(m), \tau_{2}(l)\right\rangle, \alpha\right) \leftarrow(1-\beta) \times Q\left(\left\langle\tau_{1}(m), \tau_{2}(l)\right\rangle, \alpha\right)+ \\
\beta \times\left(r\left(\left\langle\tau_{1}(m), \tau_{2}(l)\right\rangle, \alpha\right)+\gamma \max _{\alpha^{\prime}} Q\left(\left\langle\tau_{1}(x), \tau_{2}(y)\right\rangle, \alpha^{\prime}\right)\right.
\end{aligned}
$$

Update the normalized LNFE and LNFV of $\boldsymbol{\psi}_{k}$ as

$$
\mu_{k-\text { norm }} \leftarrow \mu_{k-\text { norm }}^{\text {cur }} \text { and } \vartheta_{k-\text { norm }} \leftarrow \vartheta_{k-\text { norm }}^{\text {cur }} .
$$

\section{EXPERIMENTS AND RESULTS}

\section{A. Benchmark Functions and Performance Metric}

Noisy versions of 28 single objective benchmark functions proposed in CEC'2013 [26] are used here to compare the performance of the QLNBC algorithm with its contenders in 
the presence of noise (in the fitness landscape) following Gaussian [27], Poisson [28], Rayleigh [29], exponential [30] and random [31] distribution. Function error value (FEV) is considered as the performance metric for the comparative analysis. For a particular benchmark function $f$, FEV is represented by

$$
F E V(f)=\left|f^{*}-f^{m e d}\right|
$$

where $f^{\text {med }}$ denotes the median of the best fitness values obtained by an algorithm over $R$ runs (say 50) and $f^{*}$ represents the true optimum value of $f$. Smaller the FEV, better is the performance of an algorithm.

\section{B. Comparative Framework}

The comparative framework is formed by considering a few widely popular noisy single objective optimization algorithms (NSOOAs), including learning automata induced noisy bee colony (LANBC) [21], memetic for uncertainties DE (MUDE) [22], subset based LA incorporated particle swarm optimization (LAPSO) [23], and noise tolerant genetic algorithm (NTGA) [24]. In the present work, the sampling strategy of extended LANBC [25] is replaced with the proposed TDQL induced adaptive sampling policy while keeping other strategies embedded in extended LANBC unchanged. The new contender algorithm thus developed is referred to as extended QLNBC henceforth and is regarded as new member of the comparative framework.

\section{Results and Performance Analysis}

Comparative performance analysis of the proposed algorithms (QLNBC and extended QLNBC) with their contenders is undertaken in this section. The performance analysis is carried out for all possible noise distribution in the fitness landscape. However, a few results are reported for space restriction.
The median FEV values obtained by all seven contenders over 50 independent runs are reported in Table-I with corresponding interquartile range (within parenthesis). Noise samples taken from zero mean Gaussian distribution of variance 0.57 are used to additively contaminate the benchmark functions to test the accuracy of the algorithms. Statistical significance of superiority of one algorithm over others is assessed by Wilcoxon rank sum test [32] with a significance level of 0.05 . The test is undertaken between the best algorithm (providing the minimum median FEV value) and the rest and the respective $p$-value thus obtained is reported in the third bracket for each benchmark instance. Here NA denotes not applicable cases of comparing the best algorithm with itself. The null hypothesis is concerned with statistically equivalent performance of the best algorithm and each of the remaining contenders. The null hypothesis is rejected on obtaining the corresponding $p$-value less than 0.05 .

It is evident from Table-I that extended QLNBC outperforms its contenders in 19 cases out of 28 benchmark functions. Out of these 19 cases, 17 cases reveal statistically significant superiority of the extended QLNBC to its contenders. In case of $\mathrm{f} 10$ and $\mathrm{f} 15$, extended QLNBC marginally outperforms extended LANBC, though not significantly. However, extended QLNBC is outperformed by extended LANBC in case of $\mathrm{f} 13$ and $\mathrm{f} 23$. QLNBC supersedes its extended version for $\mathrm{f} 20$. The performance difference is however statistically insignificant. For f01-f03, f17, f19 and f26, both extended QLNBC and extended LANBC achieve the same accuracy. The interquartile range obtained by extended LANBC for f17 and f19 is however more than that of extended QLNBC. Similar performance of QLNBC and its extended counterpart is also noted for f01 and $\mathrm{f} 02$.

TABLE I-A: FEVs of NSOOAs In PRESENCE of ZERo MEAN GAUSSIAN NoISE (OF VARIANCE =0.57) IN FITNESS LANDSCAPE f01 TO f08

\begin{tabular}{|c|c|c|c|c|c|c|c|}
\hline Functions & Ext. QLNBC & Ext. LANBC & QLNBC & LANBC & MUDE & LAPSO & NTGA \\
\hline f01 & $\begin{array}{c}0.00 \mathrm{e}+000 \\
(0.00 \mathrm{e}+000) \\
\text { NA }\end{array}$ & $\begin{array}{c}0.00 \mathrm{e}+000 \\
(0.00 \mathrm{e}+000) \\
\text { NA }\end{array}$ & $\begin{array}{c}0.00 \mathrm{e}+000 \\
(0.00 \mathrm{e}+000) \\
\text { NA }\end{array}$ & $\begin{array}{c}0.00 \mathrm{e}+000 \\
(0.00 \mathrm{e}+000) \\
\text { NA }\end{array}$ & $\begin{array}{c}1.89 \mathrm{e}-007 \\
(1.25 \mathrm{e}-008) \\
{[3.86 \mathrm{e}-005]}\end{array}$ & $\begin{array}{c}2.13 \mathrm{e}-007 \\
(3.31 \mathrm{e}-008) \\
{[1.94 \mathrm{e}-005]}\end{array}$ & $\begin{array}{c}3.95 \mathrm{e}-007 \\
(6.16 \mathrm{e}-008) \\
{[4.30 \mathrm{e}-006]}\end{array}$ \\
\hline $\mathrm{f} 02$ & $\begin{array}{c}0.00 \mathrm{e}+000 \\
(0.00 \mathrm{e}+000) \\
\text { NA } \\
\end{array}$ & $\begin{array}{c}0.00 \mathrm{e}+000 \\
(0.00 \mathrm{e}+000) \\
\text { NA } \\
\end{array}$ & $\begin{array}{c}0.00 \mathrm{e}+000 \\
(0.00 \mathrm{e}+000) \\
\text { NA } \\
\end{array}$ & $\begin{array}{c}5.67 \mathrm{e}-004 \\
(5.56 \mathrm{e}+001) \\
{[1.45 \mathrm{e}-003]} \\
\end{array}$ & $\begin{array}{c}7.95 \mathrm{e}-004 \\
(1.24 \mathrm{e}+002) \\
{[3.91 \mathrm{e}-004]}\end{array}$ & $\begin{array}{c}1.27 \mathrm{e}-003 \\
(9.09 \mathrm{e}+002) \\
55.48 \mathrm{e}-006]\end{array}$ & $\begin{array}{c}1.61 \mathrm{e}-003 \\
(1.10 \mathrm{e}+004) \\
{[2.28 \mathrm{e}-006]}\end{array}$ \\
\hline f03 & $\begin{array}{c}0.00 \mathrm{e}+000 \\
(0.00 \mathrm{e}+000) \\
\text { NA }\end{array}$ & $\begin{array}{c}0.00 \mathrm{e}+000 \\
(0.00 \mathrm{e}+000) \\
\text { NA }\end{array}$ & $\begin{array}{c}7.21 \mathrm{e}-003 \\
(8.33 \mathrm{e}+001) \\
{[4.86 \mathrm{e}-002]}\end{array}$ & $\begin{array}{c}7.90 \mathrm{e}-003 \\
(1.64 \mathrm{e}+002) \\
{[4.83 \mathrm{e}-002]}\end{array}$ & $\begin{array}{c}1.08 \mathrm{e}-002 \\
(2.16 \mathrm{e}+002) \\
{[4.50 \mathrm{e}-002]}\end{array}$ & $\begin{array}{c}6.69 \mathrm{e}-002 \\
(2.51 \mathrm{e}+002) \\
{[1.53 \mathrm{e}-002]}\end{array}$ & $\begin{array}{c}1.48 \mathrm{e}-001 \\
(2.68 \mathrm{e}+002) \\
{[6.47 \mathrm{e}-003]}\end{array}$ \\
\hline f04 & $\begin{array}{c}5.17 \mathrm{e}-005 \\
(2.99 \mathrm{e}-005) \\
\text { NA } \\
\end{array}$ & $\begin{array}{c}1.05 \mathrm{e}-004 \\
(7.83 \mathrm{e}-005) \\
{[3.01 \mathrm{e}-003]}\end{array}$ & $\begin{array}{c}3.62 \mathrm{e}-004 \\
(5.22 \mathrm{e}-004) \\
{[2.67 \mathrm{e}-003]}\end{array}$ & $\begin{array}{c}3.74 \mathrm{e}-003 \\
(6.30 \mathrm{e}-004) \\
{[2.41 \mathrm{e}-003]}\end{array}$ & $\begin{array}{c}5.01 \mathrm{e}-003 \\
(9.01 \mathrm{e}-004) \\
{[3.04 \mathrm{e}-004]}\end{array}$ & $\begin{array}{c}6.84 \mathrm{e}-003 \\
(1.13 \mathrm{e}-001) \\
{[1.23 \mathrm{e}-004]}\end{array}$ & $\begin{array}{c}1.26 \mathrm{e}-002 \\
(1.64 \mathrm{e}+000) \\
{[2.73 \mathrm{e}-005]}\end{array}$ \\
\hline f05 & $\begin{array}{c}0.00 \mathrm{e}+000 \\
(0.00 \mathrm{e}+000) \\
\text { NA } \\
\end{array}$ & $\begin{array}{c}1.51 \mathrm{e}-008 \\
(4.82 \mathrm{e}-004) \\
{[4.74 \mathrm{e}-005]}\end{array}$ & $\begin{array}{c}9.05 \mathrm{e}-008 \\
(1.34 \mathrm{e}-003) \\
{[1.67 \mathrm{e}-005]}\end{array}$ & $\begin{array}{c}1.99 \mathrm{e}-006 \\
(3.48 \mathrm{e}-003) \\
{[4.61 \mathrm{e}-007]}\end{array}$ & $\begin{array}{c}2.16 \mathrm{e}-006 \\
(3.84 \mathrm{e}-003) \\
{[4.24 \mathrm{e}-007]}\end{array}$ & $\begin{array}{c}1.47 \mathrm{e}-005 \\
(4.55 \mathrm{e}-003) \\
{[4.09 \mathrm{e}-007]}\end{array}$ & $\begin{array}{c}5.16 \mathrm{e}-005 \\
(5.61 \mathrm{e}-003) \\
{[1.14 \mathrm{e}-007]}\end{array}$ \\
\hline f06 & $\begin{array}{c}1.55 \mathrm{e}+001 \\
(6.65 \mathrm{e}-006) \\
\text { NA }\end{array}$ & $\begin{array}{c}2.86 \mathrm{e}+001 \\
(7.48 \mathrm{e}-002) \\
{[1.43 \mathrm{e}-003]}\end{array}$ & $\begin{array}{c}3.10 \mathrm{e}+001 \\
(1.45 \mathrm{e}+000) \\
{[1.23 \mathrm{e}-004]}\end{array}$ & $\begin{array}{c}3.83 \mathrm{e}+001 \\
(3.02 \mathrm{e}+000) \\
{[4.10 \mathrm{e}-005]}\end{array}$ & $\begin{array}{c}4.05 \mathrm{e}+001 \\
(6.46 \mathrm{e}+000) \\
{[1.95 \mathrm{e}-006]}\end{array}$ & $\begin{array}{c}4.08 \mathrm{e}+001 \\
(7.38 \mathrm{e}+000) \\
{[1.56 \mathrm{e}-006]}\end{array}$ & $\begin{array}{c}4.27 \mathrm{e}+001 \\
(9.04 \mathrm{e}+000) \\
{[2.30 \mathrm{e}-007]}\end{array}$ \\
\hline f07 & $\begin{array}{c}3.71 \mathrm{e}+000 \\
(3.25 \mathrm{e}+000) \\
\text { NA }\end{array}$ & $\begin{array}{c}3.43 \mathrm{e}+001 \\
(5.72 \mathrm{e}+000) \\
{[1.10 \mathrm{e}-003]}\end{array}$ & $\begin{array}{c}3.56 \mathrm{e}+001 \\
(6.69 \mathrm{e}+000) \\
{[3.17 \mathrm{e}-005]}\end{array}$ & $\begin{array}{c}3.75 \mathrm{e}+001 \\
(9.16 \mathrm{e}+000) \\
{[2.40 \mathrm{e}-005]}\end{array}$ & $\begin{array}{c}4.48 \mathrm{e}+001 \\
(9.18 \mathrm{e}+000) \\
{[1.33 \mathrm{e}-006]}\end{array}$ & $\begin{array}{c}4.78 \mathrm{e}+001 \\
(9.71 \mathrm{e}+000) \\
{[7.97 \mathrm{e}-006]}\end{array}$ & $\begin{array}{c}6.37 \mathrm{e}+001 \\
(1.10 \mathrm{e}+001) \\
{[7.52 \mathrm{e}-007]}\end{array}$ \\
\hline f08 & $\begin{array}{c}2.08 \mathrm{e}+001 \\
(2.96 \mathrm{e}-002) \\
\text { NA } \\
\end{array}$ & $\begin{array}{c}2.09 \mathrm{e}+001 \\
(3.58 \mathrm{e}-002) \\
{[3.56 \mathrm{e}-002]}\end{array}$ & $\begin{array}{c}2.10 \mathrm{e}+001 \\
(4.23 \mathrm{e}-002) \\
{[1.47 \mathrm{e}-002]}\end{array}$ & $\begin{array}{c}2.10 \mathrm{e}+001 \\
(4.64 \mathrm{e}-002) \\
{[1.03 \mathrm{e}-002]}\end{array}$ & $\begin{array}{c}2.10 \mathrm{e}+001 \\
(4.65 \mathrm{e}-002) \\
{[5.38 \mathrm{e}-003]}\end{array}$ & $\begin{array}{c}2.10 \mathrm{e}+001 \\
(5.19 \mathrm{e}-002) \\
{[5.15 \mathrm{e}-003]}\end{array}$ & $\begin{array}{c}2.10 \mathrm{e}+001 \\
(6.20 \mathrm{e}-002) \\
{[4.93 \mathrm{e}-003]}\end{array}$ \\
\hline
\end{tabular}




\begin{tabular}{|c|c|c|c|c|c|c|c|}
\hline Functions & Ext. QLNBC & Ext. LANBC & QLNBC & LANBC & MUDE & LAPSO & NTGA \\
\hline f09 & $\begin{array}{c}1.16 \mathrm{e}+001 \\
(1.27 \mathrm{e}+000) \\
\text { NA }\end{array}$ & $\begin{array}{c}1.66 \mathrm{e}+001 \\
(2.27 \mathrm{e}+000) \\
{[5.94 \mathrm{e}-002]}\end{array}$ & $\begin{array}{c}3.40 \mathrm{e}+001 \\
(2.29 \mathrm{e}+000) \\
{[5.57 \mathrm{e}-002\rceil}\end{array}$ & $\begin{array}{c}4.37 \mathrm{e}+001 \\
(2.46 \mathrm{e}+000) \\
{[5.07 \mathrm{e}-002\rceil}\end{array}$ & $\begin{array}{c}4.90 \mathrm{e}+001 \\
(2.86 \mathrm{e}+000) \\
{[4.18 \mathrm{e}-002]}\end{array}$ & $\begin{array}{c}4.98 \mathrm{e}+001 \\
(3.33 \mathrm{e}+000) \\
{[1.48 \mathrm{e}-002]}\end{array}$ & $\begin{array}{c}5.05 \mathrm{e}+001 \\
(3.60 \mathrm{e}+000) \\
{[9.40 \mathrm{e}-004]}\end{array}$ \\
\hline $\mathrm{f} 10$ & $\begin{array}{c}5.14 \mathrm{e}-008 \\
(4.12 \mathrm{e}-005) \\
\text { NA }\end{array}$ & $\begin{array}{c}5.35 \mathrm{e}-004 \\
(7.22 \mathrm{e}-002) \\
{[5.10 \mathrm{e}-002]}\end{array}$ & $\begin{array}{c}7.55 \mathrm{e}-004 \\
(1.19 \mathrm{e}-003) \\
{[2.36 \mathrm{e}-004]}\end{array}$ & $\begin{array}{c}5.14 \mathrm{e}-003 \\
(3.64 \mathrm{e}-003) \\
{[3.02 \mathrm{e}-006]}\end{array}$ & $\begin{array}{c}1.25 \mathrm{e}-002 \\
(1.15 \mathrm{e}-002) \\
{[2.59 \mathrm{e}-006]}\end{array}$ & $\begin{array}{c}1.75 \mathrm{e}-002 \\
(1.28 \mathrm{e}-002) \\
{[3.22 \mathrm{e}-006}\end{array}$ & $\begin{array}{c}2.57 \mathrm{e}-002 \\
(1.37 \mathrm{e}-002) \\
{[3.03 \mathrm{e}-007]}\end{array}$ \\
\hline f11 & $\begin{array}{c}7.88 \mathrm{e}-001 \\
(1.27 \mathrm{e}-003) \\
\text { NA }\end{array}$ & $\begin{array}{c}3.27 \mathrm{e}+000 \\
(4.21 \mathrm{e}-002) \\
{[2.97 \mathrm{e}-003]}\end{array}$ & $\begin{array}{c}5.50 \mathrm{e}+000 \\
(9.88 \mathrm{e}-002) \\
{[1.26 \mathrm{e}-003]}\end{array}$ & $\begin{array}{c}5.74 \mathrm{e}+000 \\
(1.21 \mathrm{e}-001) \\
{[3.42 \mathrm{e}-004]}\end{array}$ & $\begin{array}{c}7.43 \mathrm{e}+000 \\
(3.21 \mathrm{e}-001) \\
{[3.35 \mathrm{e}-004]}\end{array}$ & $\begin{array}{c}1.54 \mathrm{e}+001 \\
(1.92 \mathrm{e}+000) \\
{[9.09 \mathrm{e}-005]}\end{array}$ & $\begin{array}{c}1.69 \mathrm{e}+001 \\
(2.59 \mathrm{e}+000) \\
{[3.95 \mathrm{e}-006]}\end{array}$ \\
\hline f12 & $\begin{array}{c}9.72 \mathrm{e}+000 \\
(1.86 \mathrm{e}+000) \\
\mathrm{NA}\end{array}$ & $\begin{array}{c}2.69 \mathrm{e}+001 \\
(2.78 \mathrm{e}+000) \\
{[3.41 \mathrm{e}-004]}\end{array}$ & $\begin{array}{c}4.20 \mathrm{e}+001 \\
(7.71 \mathrm{e}+000) \\
{[2.50 \mathrm{e}-004]}\end{array}$ & $\begin{array}{c}6.63 \mathrm{e}+001 \\
(9.46 \mathrm{e}+000) \\
{[1.86 \mathrm{e}-004]}\end{array}$ & $\begin{array}{c}8.55 \mathrm{e}+001 \\
(2.09 \mathrm{e}+001) \\
{[2.47 \mathrm{e}-005]}\end{array}$ & $\begin{array}{c}9.65 \mathrm{e}+001 \\
(2.27 \mathrm{e}+001) \\
{[2.02 \mathrm{e}-006]}\end{array}$ & $\begin{array}{c}1.32 \mathrm{e}+002 \\
(3.26 \mathrm{e}+001) \\
{[3.05 \mathrm{e}-007]}\end{array}$ \\
\hline f13 & $\begin{array}{c}8.05 \mathrm{e}+001 \\
(7.92 \mathrm{e}+000) \\
{[9.93 \mathrm{e}-003]}\end{array}$ & $\begin{array}{c}4.55 \mathrm{e}+001 \\
(2.68 \mathrm{e}+000) \\
\text { NA }\end{array}$ & $\begin{array}{c}9.26 \mathrm{e}+001 \\
(1.89 \mathrm{e}+001) \\
{[9.78 \mathrm{e}-003]}\end{array}$ & $\begin{array}{c}1.41 \mathrm{e}+002 \\
(1.99 \mathrm{e}+001) \\
{[2.20 \mathrm{e}-004]}\end{array}$ & $\begin{array}{c}1.48 \mathrm{e}+002 \\
(2.27 \mathrm{e}+001) \\
{[1.79 \mathrm{e}-004]}\end{array}$ & $\begin{array}{c}1.84 \mathrm{e}+002 \\
(3.07 \mathrm{e}+001) \\
{[2.99 \mathrm{e}-004]}\end{array}$ & $\begin{array}{c}1.96 \mathrm{e}+002 \\
(3.37 \mathrm{e}+001) \\
{[2.78 \mathrm{e}-005]}\end{array}$ \\
\hline f14 & $\begin{array}{c}1.37 \mathrm{e}+001 \\
(5.73 \mathrm{e}+000) \\
\text { NA }\end{array}$ & $\begin{array}{c}2.06 \mathrm{e}+001 \\
(8.55 \mathrm{e}+000) \\
{[4.91 \mathrm{e}-003]}\end{array}$ & $\begin{array}{c}2.75 \mathrm{e}+001 \\
(1.03 \mathrm{e}+001) \\
{[3.79 \mathrm{e}-003]}\end{array}$ & $\begin{array}{c}2.19 \mathrm{e}+002 \\
(7.45 \mathrm{e}+001) \\
{[1.57 \mathrm{e}-004]}\end{array}$ & $\begin{array}{c}5.38 \mathrm{e}+002 \\
(1.83 \mathrm{e}+002) \\
{[1.46 \mathrm{e}-005]}\end{array}$ & $\begin{array}{c}7.48 \mathrm{e}+002 \\
(2.65 \mathrm{e}+002) \\
{[4.52 \mathrm{e}-006]}\end{array}$ & $\begin{array}{c}7.90 \mathrm{e}+002 \\
(4.48 \mathrm{e}+002) \\
{[7.25 \mathrm{e}-006]}\end{array}$ \\
\hline f15 & $\begin{array}{c}1.09 \mathrm{e}+003 \\
(2.83 \mathrm{e}+002) \\
\text { NA }\end{array}$ & $\begin{array}{c}2.18 \mathrm{e}+003 \\
(3.67 \mathrm{e}+002) \\
{[5.47 \mathrm{e}-002]}\end{array}$ & $\begin{array}{c}2.28 \mathrm{e}+003 \\
(4.32 \mathrm{e}+002) \\
{[4.39 \mathrm{e}-002]}\end{array}$ & $\begin{array}{c}4.36 \mathrm{e}+003 \\
(4.38 \mathrm{e}+002) \\
{[6.97 \mathrm{e}-003]}\end{array}$ & $\begin{array}{c}6.35 \mathrm{e}+003 \\
(5.31 \mathrm{e}+002) \\
{[4.97 \mathrm{e}-004]}\end{array}$ & $\begin{array}{c}6.47 \mathrm{e}+003 \\
(5.51 \mathrm{e}+002) \\
{[5.84 \mathrm{e}-005]}\end{array}$ & $\begin{array}{c}7.42 \mathrm{e}+003 \\
(6.30 \mathrm{e}+002) \\
{[3.89 \mathrm{e}-006]}\end{array}$ \\
\hline f16 & $\begin{array}{c}3.84 \mathrm{e}-001 \\
(3.21 \mathrm{e}-002) \\
\text { NA } \\
\end{array}$ & $\begin{array}{c}7.84 \mathrm{e}-001 \\
(4.23 \mathrm{e}-002) \\
{[1.26 \mathrm{e}-003]}\end{array}$ & $\begin{array}{c}1.07 \mathrm{e}+000 \\
(1.68 \mathrm{e}-001) \\
{[5.16 \mathrm{e}-004]}\end{array}$ & $\begin{array}{c}1.46 \mathrm{e}+000 \\
(1.96 \mathrm{e}-001) \\
{[4.89 \mathrm{e}-004]}\end{array}$ & $\begin{array}{c}1.63 \mathrm{e}+000 \\
(2.03 \mathrm{e}-001) \\
{[3.22 \mathrm{e}-004]}\end{array}$ & $\begin{array}{c}1.72 \mathrm{e}+000 \\
(2.35 \mathrm{e}-001) \\
{[5.01 \mathrm{e}-005]}\end{array}$ & $\begin{array}{c}2.12 \mathrm{e}+000 \\
(2.81 \mathrm{e}-001) \\
{[5.33 \mathrm{e}-006]}\end{array}$ \\
\hline f17 & $\begin{array}{c}4.36 \mathrm{e}+001 \\
(2.58 \mathrm{e}-003) \\
\text { NA }\end{array}$ & $\begin{array}{c}.36 \mathrm{e}+001 \\
(3.17 \mathrm{e}-002) \\
\text { NA }\end{array}$ & $\begin{array}{c}5.07 \mathrm{e}+001 \\
(4.10 \mathrm{e}-001) \\
{[6.95 \mathrm{e}-003]}\end{array}$ & $\begin{array}{c}5.40 \mathrm{e}+001 \\
(1.12 \mathrm{e}+000) \\
{[9.15 \mathrm{e}-004]}\end{array}$ & $\begin{array}{c}5.65 \mathrm{e}+001 \\
(1.77 \mathrm{e}+000) \\
{[5.02 \mathrm{e}-005]}\end{array}$ & $\begin{array}{c}6.55 \mathrm{e}+001 \\
(2.37 \mathrm{e}+000) \\
{[3.47 \mathrm{e}-005]}\end{array}$ & $\begin{array}{c}7.37 \mathrm{e}+001 \\
(4.29 \mathrm{e}+000) \\
{[2.84 \mathrm{e}-007]}\end{array}$ \\
\hline f18 & $\begin{array}{c}6.60 \mathrm{e}+001 \\
(1.17 \mathrm{e}+001) \\
\text { NA }\end{array}$ & $\begin{array}{c}1.09 \mathrm{e}+002 \\
(1.33 \mathrm{e}+001) \\
{[1.27 \mathrm{e}-002]}\end{array}$ & $\begin{array}{c}1.26 \mathrm{e}+002 \\
(1.61 \mathrm{e}+001) \\
{[5.24 \mathrm{e}-002]}\end{array}$ & $\begin{array}{c}1.30 \mathrm{e}+002 \\
(2.87 \mathrm{e}+001) \\
{[6.73 \mathrm{e}-004]}\end{array}$ & $\begin{array}{c}1.48 \mathrm{e}+002 \\
(3.33 \mathrm{e}+001) \\
{[2.10 \mathrm{e}-004]}\end{array}$ & $\begin{array}{c}1.53 \mathrm{e}+002 \\
(3.64 \mathrm{e}+001) \\
{[2.77 \mathrm{e}-004]}\end{array}$ & $\begin{array}{c}1.67 \mathrm{e}+002 \\
(4.48 \mathrm{e}+001) \\
{[2.58 \mathrm{e}-005]}\end{array}$ \\
\hline f19 & $\begin{array}{c}2.13 \mathrm{e}+000 \\
(2.91 \mathrm{e}-001) \\
\text { NA }\end{array}$ & $\begin{array}{c}2.13 \mathrm{e}+000 \\
(3.51 \mathrm{e}-001) \\
\text { NA }\end{array}$ & $\begin{array}{c}3.38 \mathrm{e}+000 \\
(4.69 \mathrm{e}-001) \\
{[1.26 \mathrm{e}-004]}\end{array}$ & $\begin{array}{c}3.42 \mathrm{e}+000 \\
(4.89 \mathrm{e}-001) \\
{[3.20 \mathrm{e}-005]}\end{array}$ & $\begin{array}{c}3.84 \mathrm{e}+000 \\
(6.74 \mathrm{e}-001) \\
{[3.39 \mathrm{e}-006]}\end{array}$ & $\begin{array}{c}3.89 \mathrm{e}+000 \\
(7.24 \mathrm{e}-001) \\
{[1.08 \mathrm{e}-006]}\end{array}$ & $\begin{array}{c}4.33 \mathrm{e}+000 \\
(7.96 \mathrm{e}-001) \\
{[8.63 \mathrm{e}-007]}\end{array}$ \\
\hline $\mathrm{f} 20$ & $\begin{array}{c}1.89 \mathrm{e}+001 \\
(4.44 \mathrm{e}-001) \\
{[5.54 \mathrm{e}-002]}\end{array}$ & $\begin{array}{c}1.91 \mathrm{e}+001 \\
(5.39 \mathrm{e}-001) \\
{[3.91 \mathrm{e}-003]}\end{array}$ & $\begin{array}{c}1.40 \mathrm{e}+001 \\
(3.86 \mathrm{e}-001) \\
\text { NA }\end{array}$ & $\begin{array}{c}1.91 \mathrm{e}+001 \\
(5.84 \mathrm{e}-001) \\
{[3.41 \mathrm{e}-004]}\end{array}$ & $\begin{array}{c}1.94 \mathrm{e}+001 \\
(6.55 \mathrm{e}-001) \\
{[2.75 \mathrm{e}-004]}\end{array}$ & $\begin{array}{c}2.01 \mathrm{e}+001 \\
(7.85 \mathrm{e}-001) \\
{[2.01 \mathrm{e}-004]}\end{array}$ & $\begin{array}{c}2.05 \mathrm{e}+001 \\
(7.96 \mathrm{e}-001) \\
{[1.36 \mathrm{e}-005]}\end{array}$ \\
\hline $\mathrm{f} 21$ & $\begin{array}{c}2.28 \mathrm{e}+002 \\
(1.07 \mathrm{e}+001) \\
\text { NA }\end{array}$ & $\begin{array}{c}2.38 \mathrm{e}+002 \\
(4.03 \mathrm{e}+001) \\
{[3.03 \mathrm{e}-004\rceil}\end{array}$ & $\begin{array}{c}2.45 \mathrm{e}+002 \\
(1.83 \mathrm{e}+002) \\
{[1.01 \mathrm{e}-004\rceil}\end{array}$ & $\begin{array}{c}2.96 \mathrm{e}+002 \\
(2.27 \mathrm{e}+002) \\
{[6.27 \mathrm{e}-005]}\end{array}$ & $\begin{array}{l}3.72 \mathrm{e}+002 \\
(2.73 \mathrm{e}+002) \\
{[5.42 \mathrm{e}-005]}\end{array}$ & $\begin{array}{c}5.08 \mathrm{e}+002 \\
(2.88 \mathrm{e}+002) \\
{[1.17 \mathrm{e}-006]}\end{array}$ & $\begin{array}{c}6.30 \mathrm{e}+002 \\
(3.25 \mathrm{e}+002) \\
{[8.20 \mathrm{e}-007]}\end{array}$ \\
\hline $\mathrm{f} 22$ & $\begin{array}{c}2.43 \mathrm{e}+001 \\
(1.46 \mathrm{e}+001) \\
\text { NA }\end{array}$ & $\begin{array}{c}2.79 \mathrm{e}+001 \\
(2.57 \mathrm{e}+001) \\
{[2.62 \mathrm{e}-003]}\end{array}$ & $\begin{array}{c}4.37 \mathrm{e}+001 \\
(4.07 \mathrm{e}+001) \\
{[1.01 \mathrm{e}-003]}\end{array}$ & $\begin{array}{c}2.79 \mathrm{e}+002 \\
(4.93 \mathrm{e}+001) \\
{[6.66 \mathrm{e}-004]}\end{array}$ & $\begin{array}{c}3.38 \mathrm{e}+002 \\
(2.66 \mathrm{e}+002) \\
{[6.49 \mathrm{e}-005]}\end{array}$ & $\begin{array}{c}5.70 \mathrm{e}+002 \\
(3.55 \mathrm{e}+002) \\
{[3.03 \mathrm{e}-007]}\end{array}$ & $\begin{array}{c}5.97 \mathrm{e}+002 \\
(3.61 \mathrm{e}+002) \\
{[1.41 \mathrm{e}-007]}\end{array}$ \\
\hline $\mathrm{f} 23$ & $\begin{array}{c}1.85 \mathrm{e}+003 \\
(3.63 \mathrm{e}+002) \\
{[1.48 \mathrm{e}-002]}\end{array}$ & $\begin{array}{c}8.04 \mathrm{e}+002 \\
(3.26 \mathrm{e}+002) \\
\text { NA }\end{array}$ & $\begin{array}{c}2.91 \mathrm{e}+003 \\
(5.35 \mathrm{e}+002) \\
{[1.07 \mathrm{e}-003]}\end{array}$ & $\begin{array}{c}6.51 \mathrm{e}+003 \\
(5.52 \mathrm{e}+002) \\
{[1.11 \mathrm{e}-004]}\end{array}$ & $\begin{array}{c}7.23 \mathrm{e}+003 \\
(6.52 \mathrm{e}+002) \\
{[1.00 \mathrm{e}-005]}\end{array}$ & $\begin{array}{c}8.25 \mathrm{e}+003 \\
(7.36 \mathrm{e}+002) \\
{[2.41 \mathrm{e}-006}\end{array}$ & $\begin{array}{c}8.79 \mathrm{e}+003 \\
(8.98 \mathrm{e}+002) \\
{[3.16 \mathrm{e}-0071}\end{array}$ \\
\hline $\mathrm{f} 24$ & $\begin{array}{c}2.23 \mathrm{e}+002 \\
(2.23 \mathrm{e}+000) \\
\text { (a) }\end{array}$ & $\begin{array}{c}2.26 \mathrm{e}+002 \\
(5.53 \mathrm{e}+000) \\
{[5.60 \mathrm{e}-003}\end{array}$ & $\begin{array}{c}2.36 \mathrm{e}+002 \\
(9.34 \mathrm{e}+000) \\
55.53 \mathrm{e}-003]\end{array}$ & $\begin{array}{c}2.80 \mathrm{e}+002 \\
(1.18 \mathrm{e}+001) \\
{[1.25 \mathrm{e}-003}\end{array}$ & $\begin{array}{c}2.82 \mathrm{e}+002 \\
(1.40 \mathrm{e}+001) \\
\end{array}$ & $\begin{array}{c}2.84 \mathrm{e}+002 \\
(1.70 \mathrm{e}+001) \\
22.21 \mathrm{e}-005\end{array}$ & $\begin{array}{c}3.07 \mathrm{e}+002 \\
(1.95 \mathrm{e}+001) \\
{[4.29 \mathrm{e}-0071}\end{array}$ \\
\hline $\mathrm{f} 25$ & $\begin{array}{c}2.25 \mathrm{e}+002 \\
(3.97 \mathrm{e}+000) \\
\text { NA }\end{array}$ & $\begin{array}{c}3.01 \mathrm{e}+002 \\
(8.01 \mathrm{e}+000) \\
{[4.89 \mathrm{e}-005]}\end{array}$ & $\begin{array}{c}3.05 \mathrm{e}+002 \\
(1.01 \mathrm{e}+001) \\
{[4.60 \mathrm{e}-005]}\end{array}$ & $\begin{array}{c}3.14 \mathrm{e}+002 \\
(1.05 \mathrm{e}+001) \\
{[2.98 \mathrm{e}-005]}\end{array}$ & $\begin{array}{c}3.26 \mathrm{e}+002 \\
(1.21 \mathrm{e}+001) \\
{[9.21 \mathrm{e}-006]}\end{array}$ & $\begin{array}{c}3.37 \mathrm{e}+002 \\
(1.47 \mathrm{e}+001) \\
{[2.77 \mathrm{e}-006]}\end{array}$ & $\begin{array}{c}3.60 \mathrm{e}+002 \\
(1.83 \mathrm{e}+001) \\
{[7.83 \mathrm{e}-007]}\end{array}$ \\
\hline f26 & $\begin{array}{c}2.28 \mathrm{e}+001 \\
(3.68 \mathrm{e}+000) \\
\text { NA }\end{array}$ & $\begin{array}{c}2.28 \mathrm{e}+001 \\
(3.68 \mathrm{e}+000) \\
\text { NA }\end{array}$ & $\begin{array}{c}1.92 \mathrm{e}+002 \\
(2.38 \mathrm{e}+001) \\
{[5.17 \mathrm{e}-003]}\end{array}$ & $\begin{array}{c}2.40 \mathrm{e}+002 \\
(3.83 \mathrm{e}+001) \\
{[2.47 \mathrm{e}-004]}\end{array}$ & $\begin{array}{c}2.49 \mathrm{e}+002 \\
(5.88 \mathrm{e}+001) \\
{[2.07 \mathrm{e}-005]}\end{array}$ & $\begin{array}{c}2.65 \mathrm{e}+002 \\
(6.71 \mathrm{e}+001) \\
{[2.05 \mathrm{e}-006]}\end{array}$ & $\begin{array}{c}2.78 \mathrm{e}+002 \\
(9.08 \mathrm{e}+001) \\
{[9.50 \mathrm{e}-0071}\end{array}$ \\
\hline $\mathrm{f} 27$ & $\begin{array}{c}3.91 \mathrm{e}+002 \\
(3.85 \mathrm{e}+001) \\
\text { NA }\end{array}$ & $\begin{array}{c}6.87 \mathrm{e}+002 \\
(9.80 \mathrm{e}+001) \\
{[4.15 \mathrm{e}-003]}\end{array}$ & $\begin{array}{c}9.19 \mathrm{e}+002 \\
(1.36 \mathrm{e}+002) \\
{[2.42 \mathrm{e}-003]}\end{array}$ & $\begin{array}{c}9.27 \mathrm{e}+002 \\
(1.38 \mathrm{e}+002) \\
{[2.61 \mathrm{e}-004\rceil}\end{array}$ & $\begin{array}{c}9.56 \mathrm{e}+002 \\
(1.39 \mathrm{e}+002) \\
{[1.37 \mathrm{e}-005]}\end{array}$ & $\begin{array}{c}1.12 \mathrm{e}+003 \\
(1.76 \mathrm{e}+002) \\
{[9.96 \mathrm{e}-006]}\end{array}$ & $\begin{array}{c}1.38 \mathrm{e}+003 \\
(1.88 \mathrm{e}+002) \\
{[1.93 \mathrm{e}-006]}\end{array}$ \\
\hline $\mathrm{f} 28$ & $\begin{array}{c}3.83 \mathrm{e}+002 \\
(1.65 \mathrm{e}-004) \\
\text { NA }\end{array}$ & $\begin{array}{c}4.22 \mathrm{e}+002 \\
(3.55 \mathrm{e}-001) \\
{[4.11 \mathrm{e}-003]}\end{array}$ & $\begin{array}{c}4.30 \mathrm{e}+002 \\
(2.03 \mathrm{e}+001) \\
{[2.20 \mathrm{e}-003]}\end{array}$ & $\begin{array}{c}4.38 \mathrm{e}+002 \\
(8.67 \mathrm{e}+001) \\
{[1.55 \mathrm{e}-003]}\end{array}$ & $\begin{array}{c}4.58 \mathrm{e}+002 \\
(3.57 \mathrm{e}+002) \\
{[5.97 \mathrm{e}-004]}\end{array}$ & $\begin{array}{c}4.58 \mathrm{e}+002 \\
(4.17 \mathrm{e}+002) \\
{[2.85 \mathrm{e}-005]}\end{array}$ & $\begin{array}{c}5.55 \mathrm{e}+002 \\
(4.36 \mathrm{e}+002) \\
{[3.90 \mathrm{e}-005]}\end{array}$ \\
\hline
\end{tabular}

\section{CONCLUSION}

The paper proposes a novel approach to utilize the benefit of the reinforcement learning (RL) technique to judiciously assign sample size to solutions for their periodic fitness evaluation in a noisy fitness landscape. The sample size is determined based on the noisy fitness profile in the surrounding of the solutions. The fitness estimate and fitness variance of a sub-population surrounding a solution are used to capture the fitness profile in the local neighborhood of the given solution. The proposed approach detours the requirement of any specific functional form to model the relationship between the sample size of a solution and its noisy local fitness profile. TDQL is selected here as a RL mechanism to assign a small (and a large) sample size to a solution in a more (and a less) noisy zone, captured by its LNFE and LNFV. 
A relative comparison of the proposed algorithms (QLNBC and extended QLNBC) with five state-of-the-art algorithms reveals that the proposed algorithms outperform most of their competitors with respect to FEV metric. Noisy versions of a set of 28 CEC'2013 benchmark functions have been used to arrive at the foregoing conclusions. Additive noise samples taken from Gaussian, Poisson, Rayleigh, exponential and random distributions are used to realize the noisy versions of the benchmark functions. The Wilcoxon rank-sum test, the Friedman and the Iman-Davenport nonparametric tests are undertaken to affirm the statistical significance of the reported results.

\section{REFERENCES}

[1] P. Rakshit, A. Konar, and S. Das, "Noisy Evolutionary Optimization algorithms-A comprehensive survey," Swarm and Evolutionary Computation, vol. 33, 2017, pp. 18-45.

[2] Y. Jin, and J. Branke, "Evolutionary optimization in uncertain environments-a survey," IEEE Transactions on Evolutionary Computation, vol. 9, no. 3, 2005, pp. 303-317.

[3] A. D. Pietro, Optimising evolutionary strategies for problems with varying noise strength, $\mathrm{Ph}$. D. Thesis, University of Western Australia, 2007.

[4] F. Siegmund, A. H. C. Ng, and K. Deb, "Hybrid dynamic resampling for guided evolutionary multi-objective optimization," in Proceedings of Evolutionary Multi-Criterion Optimization, Springer International Publishing, 2015, pp. 366-380.

[5] G. Iacca, F. Neri, and E. Mininno, "Noise analysis compact differential evolution," International Journal of Systems Science, vol. 43, no. 7, 2012, pp. 1248-1267.

[6] C. H. Chen, J. Lin, E. Yücesan, and S. E. Chick, "Simulation budget allocation for further enhancing the efficiency of ordinal optimization," Discrete Event Dynamic Systems, vol. 10, no. 3, 2000, pp $.251-270$.

[7] P. Rakshit, A. Konar, S. Das, L. C. Jain, and A. K. Nagar, "Uncertainty management in differential evolution induced multiobjective optimization in presence of measurement noise," IEEE Transactions on Systems, Man, and Cybernetics: Systems, vol. 44, no. 7, 2014, pp. 922-937.

[8] P. Rakshit, and A. Konar, "Differential evolution for noisy multiobjective optimization," Artificial Intelligence, vol. 227, 2015, 165189.

[9] P. Rakshit, and A. Konar, "Extending multi-objective differential evolution for optimization in presence of noise," Information Sciences, vol. 305, 2015, pp. 56-76.

[10] H. Kita, and Y. Sano, "Genetic algorithms for optimization of uncertain functions and their applications," in Proceedings of SICE Annual Conference, vol. 3, 2003, pp. 2744-2749.

[11] L. T. Bui, H. A. Abbass, and D. Essam, "Fitness inheritance for noisy evolutionary multi-objective optimization," in Proceedings of the 7th Annual Conference on Genetic and Evolutionary Computation, ACM, 2005, pp. 779-785.

[12] K. C. Tan, T. H. Lee, and E. F. Khor, "Evolutionary algorithms with dynamic population size and local exploration for multiobjective optimization," IEEE Transactions on Evolutionary Computation, vol. 5, no. 6, 2001, pp. 565-588.

[13] H. G. Beyer, D. V. Arnold, and S. M. Nieberg, "A new approach for predicting the final outcome of evolution strategy optimization under noise," Genetic Programming and Evolvable Machines, vol. 6, no. 1, 2005, pp. 7-24.

[14] C. K. Goh, and K. C. Tan, "An investigation on noisy environments in evolutionary multiobjective optimization," IEEE Transactions on Evolutionary Computation, vol. 11, no. 3, 2007, pp. 354-381.

[15] Rahnamayan S., H. R. Tizhoosh, and M. Salama, "Opposition-based differential evolution for optimization of noisy problems," in
Proceedings of IEEE Congress on Evolutionary Computation, 2006, pp. 1865-1872.

[16] J. Branke, and C. Schmidt, "Selection in the presence of noise," in Proceedings of Genetic and Evolutionary Computation, Springer Berlin Heidelberg, 2003, pp. 766-777.

[17] B. L. Miller, and D. E. Goldberg, "Genetic algorithms, selection schemes, and the varying effects of noise," Evolutionary Computation, vol. 4, no. 2, 1996, pp. 113-131

[18] T. Mitchell, "Machine Learning", McGraw Hill, 1997.

[19] P. Rakshit, A. Konar, P. Bhowmik, I. Goswami, S. Das, L. C. Jain, and A. K. Nagar, "Realization of an Adaptive Memetic Algorithm Using Differential Evolution and Q-Learning: A Case Study in Multirobot Path Planning," IEEE Transactions on Systems, Man, and Cybernetics: Systems, vol. 43, no. 4, July, 2013.

[20] B. Basturk., D. Karaboga, "An artificial bee colony (ABC) algorithm for numeric function optimization," in Proceedings of the IEEE Swarm Intelligence Symposium, 2006.

[21] P. Rakshit, A. Konar, and A. K. Nagar, "Learning Automata Induced Artificial Bee Colony for Noisy Optimization," in IEEE Congress on Evolutionary Computation, 2017, pp. 984 - 991.

[22] E. Mininno, and F. Neri, "A memetic differential evolution approach in noisy optimization," Memetic Computing, vol. 2, no. 2, 2010, pp. 111135 .

[23] J. Q.Zhang, L. W. Xu, J. Ma, M. C. Zhou, "A learning automata-based particle swarm optimization algorithm for noisy environment," in IEEE Congress on Evolutionary Computation, 2015, pp. 141-147.

[24] H. Jang, R. Choe, and K. R. Ryu, "Deriving a robust policy for container stacking using a noise-tolerant genetic algorithm," in ACM Research in Applied Computation Symposium, 2012, pp. 31-36.

[25] P. Rakshit, A. Konar, and A. K. Nagar, "Modified selection and search in learning automata based artificial bee colony in noisy environment," in IEEE Congress on Evolutionary Computation, 2019, pp. 3173-3180.

[26] J. J.Liang, B. Y. Qu, P. N. Suganthan, and A. G. H. Díaz, Problem definitions and evaluation criteria for the CEC 2013 special session on real-parameter optimization, Computational Intelligence Laboratory, Zhengzhou University, Zhengzhou, China and Nanyang Technological University, Singapore, Technical Report 201212, 2013.

[27] G. E. P. Box, and M. E. Muller, "A note on the generation of random normal deviates," The annals of mathematical statistics, vol. 29, 1958, pp. 610-611.

[28] D. E. Knuth, Seminumerical Algorithms, The art of computer programming, vol. 2, 1981

[29] W. Hörmann, J. Leydold, and G. Derflinger, "General principles in random variate generation," in Automatic Nonuniform Random Variate Generation, Springer Berlin Heidelberg, 2004, pp. 13-41.

[30] G. Marsaglia, and W. W. Tsang, "The ziggurat method for generating random variables," Journal of Statistical Software, vol. 5, no. 8, 2000, pp. 1-7.

[31] J. Bolte, Linear congruential generators, Wolfram Demonstrations Project.

[32] J. Derrac, S. García, D. Molina, and F. Herrera, "A practical tutorial on the use of nonparametric statistical tests as a methodology for comparing evolutionary and swarm intelligence algorithms," Swarm and Evolutionary Computation, vol. 1, no. 1, 2011, pp. 3-18. 